\title{
CONEGUEM ELS NOSTRES ARTISTES Projecte de globalització
}

Durant aquest darrer trimestre, al C.P. de Pràctiques s'ha dut a terme un projecte de globalització artística. El seu desenvolupament ha implicat la col.laboració d'una sèrie de personatges de la nostra ciutat que destaquen per les seves aportacions en el món de les arts i que han accedit a realitzar una obra específica per als nens de la nostra escola.

\section{1.- Identificació del problema}

En el marc d'una Europa que s'encamina vers la cooperació, l'educació ha de jugar un paper fonamental. Darrerament ens estan bombardejant amb nous conceptes, noves teories... i l'arrel de tot rau en un paràmetre, en el fet que és important contemplar les activitats educatives com una tasca global, de contacte, de descobriment d'un mateix i del món que ens envolta per tal d'accedir a un òptim nivell de maduració i desenvolupament personal $i$ integral del nen.

En la nova reforma, encara que a nivell teòric, s'ha aconseguit un pas important: contemplar un apartat d'ensenyances artístiques (Música i Dansa, Arts plàstiques i Disseny i Art dramàtic). A partir d'aqui comencen a sorgir els defensors de cada una d'aquests arts intentant diferenciar els àmbits artístics. S'opta per raonaments com ara els diferents llenguatges, les diferents formes d'expressió... Es parla de la tècnica pròpia de cada un dels àmbits com si fos del tot necessari que el nen ho dominés tot, i aixi s'oblida que a l'escola no fem músics, pintors, actors de teatre... A l'escola cal educar el nen dintre d'una concepció estètico-artística holística que li potenciï unes vivències o sentiments vers la bellesa, l'harmonia dels sons, formes i colors, la necessitat de ser creador amb les seves capacitats, l'autonomia en el treball, el respecte vers el treball dels altres i la seva capacitat crítica.

En l'ensenyament primari l'educació ha de ser globalitzada. Aquest concepte s'havia entès entre els mestres. Ara, els especialistes de música, plàstica i teatre, seria absurd que intentessin esbrinar quin art és el més potenciador i el més noble. Fer això rebaixaria l'art a la categoria d'assignatura, la qual cosa ens abocaria al fracàs.

Per tot això creiem que es necessari:

- Reflexionar sobre els conceptes, procediments $i$ actituds que implica l'àrea d'ensenyança artística.

- Crear condicions i estímuls que possibilitin el desenvolupament global d'aquesta formació.

- Que els professors, mitjançant la investigació de llur pràctica, vagin creant nous models d'actuació i intervenció educativa per tal d'anar donant forma a aquesta àrea curricular.

\section{2.- Fonamentació del projecte}

A partir d'aquesta fonamentació teòrica, ens vàrem plantejar que calia optar per una Pedagogia viva que permetés al nen aprendre's a si mateix mentre compartia amb els altres l'aprenentatge de la vida.

El centre de la qüestió, com deia Giselè Barret en el primer Congrés Internacional de Teatre, celebrat a Tarragona l'any passat, rau en com reemplaçar el "saber fer" pel "saber ser". Si volem mantenir "el saber ser" com a factor prioritari per als nostres alumnes, caldrà que defugim la línia dels models educatius tancats, on la base directa de construcció són els procediments de caràcter tecnològic, els continguts com a centre de gravetat de tot el procés d'ensenyança-aprenentatge, ioptem per models de caire holístic, en els quals tots els elements tenen el mateix grau d'importància il'efecte del procés es reflecteix en cada un d'ells.

En el centre de les nostres iniciatives metodològiques s'haurien de promoure els valors, i obtenir un model educatiu que superés la mera condició de l'establiment de processos d'ensenyança-aprenentatge. Ens calia entendre la idea d'Stenhause, quan argumenta sobre educació amb termes d'art, establint una interrelació entre les maneres de fer i de comprendre aquest art. No n'hi ha prou a dir que el professor és un artista i que l'ensenyança és un art. Això, escrit així, són facècies i romanticismes absurds. L'artista es fa a través, ja no de la pràctica diària, sinó de la tossuderia i la pràctica crítica del seu art.

Experimentar depèn de l'exercici de l'art de l'ensenyança i millora el propi art. Hauriem d'experimentar molts cops allò que en un principi ens semblava correcte, però sense caure en l'error que experimentar vol dir anar provant fins que surti bé. Tota innovació ha d'estar planificada en tots els sentits $i$ aspectes del currículum, perquè és aquest, en definitiva, el contingut substantiu de l'art d'ensenyar.

Hauriem de definir i experimentar la pràctica. Clarificant i diagnosticant cada una de les situacions problemàtiques que anessin sorgint en la seva implantació. 


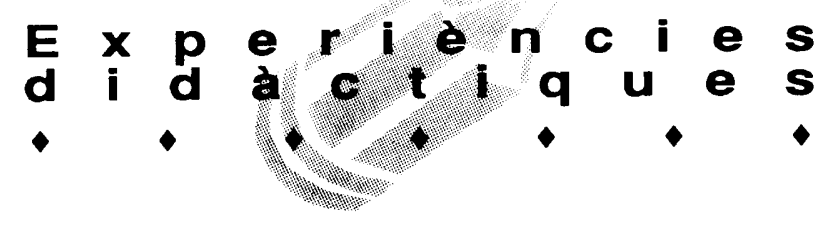

Caldria formular estratègies d'acció per resoldre els esdeveniments i problemes que, de segur, anirien sorgint.

Una innovació d'aquestes característiques es pot planificar i estructurar en el seu tarannà extern, però un cop posada en marxa és quan veritablement comença a fer-se realitat. Seria llavors, quan tots els elements del curriculum actuessin, quan caldria observar els processos de l'acció i avaluar-ne les seves conseqüències. Es aquí quan la racionalitat pràctica del professor serà valuosa, $i$ es convertirà en un explorador de la seva pròpia activitat, en un facilitador de processos de coneixement, de sensacions, percepcions $i$, en definitiva, en un crític permanent dels processos i resultats de l'acció.

Sota el mestratge d'aquesta fonamentació culturalideològica, ens vàrem posar a treballar. En primer lloc calia definir clarament l'objectiu prioritari del projecte, i fou aqui on ja va sorgir la dualitat: La nostra pretensió era fer un treball de globalització de l'art, però no podíem arraconar els artistes que el produïen ni el context social que envolta els nens.

Pensem que el nen té el dret de conèixer totes les manifestacions artístiques que es desenvolupen en la seva ciutat d'una manera coetània, aixi com els artistes $i$ intel.lectuals que conviuen amb ell en el temps. La nostra ciutat, tanmateix, té l'orgull de comptar amb un gran nombre d'artistes $i$ intel.lectuals que l'ennobleixen. Molts cops resten en l'oblit absolut, tant ells com la seva tasca. Aquest fet és llastimós, perquè en deixar-los de banda la nostra ciutat creix tecnològicament, industrialment...i s'empetiteix artísticament.

Sota aquesta reflexió, vàrem emmarcar el projecte dintre de dos objectius prioritaris: D'una banda, el fet que els nens coneguin els artistes de la nostra ciutat; i de l'altra, la presentació davant de l'alumne del concepte Art d'una forma globalitzada pertal de trencar l'esquema que tenim fins ara, on al nen se li presenten les arts per separat.

Les possibilitats eren moltes i abastaven diferents tipologies de treball. La nostra primera idea era la de globalitzar-ho tot: Música, Dansa, Teatre, Pintura, Escultura, Poesia, Narrativa... És un projecte que, un cop acabat, ens va desbordar al moment de posar-lo en pràctica. Es necessitava no solament la col.laboració de tot el centre, sinó una despesa de moltes hores i esforç per part de molta gent del col.lectiu escolar (professors, pares, alumnes, mestres, porters..) a més d'una infrastructura organitzativa que superava les nostres possibilitats.

A poc a poc ens vàrem allunyar d'aquell projecte tan pretensiós, i vàrem començar a jugar amb aquells elements que ens podien ser més útils per als nens i més propers, a partir del contacte amb els artistes. Vàrem

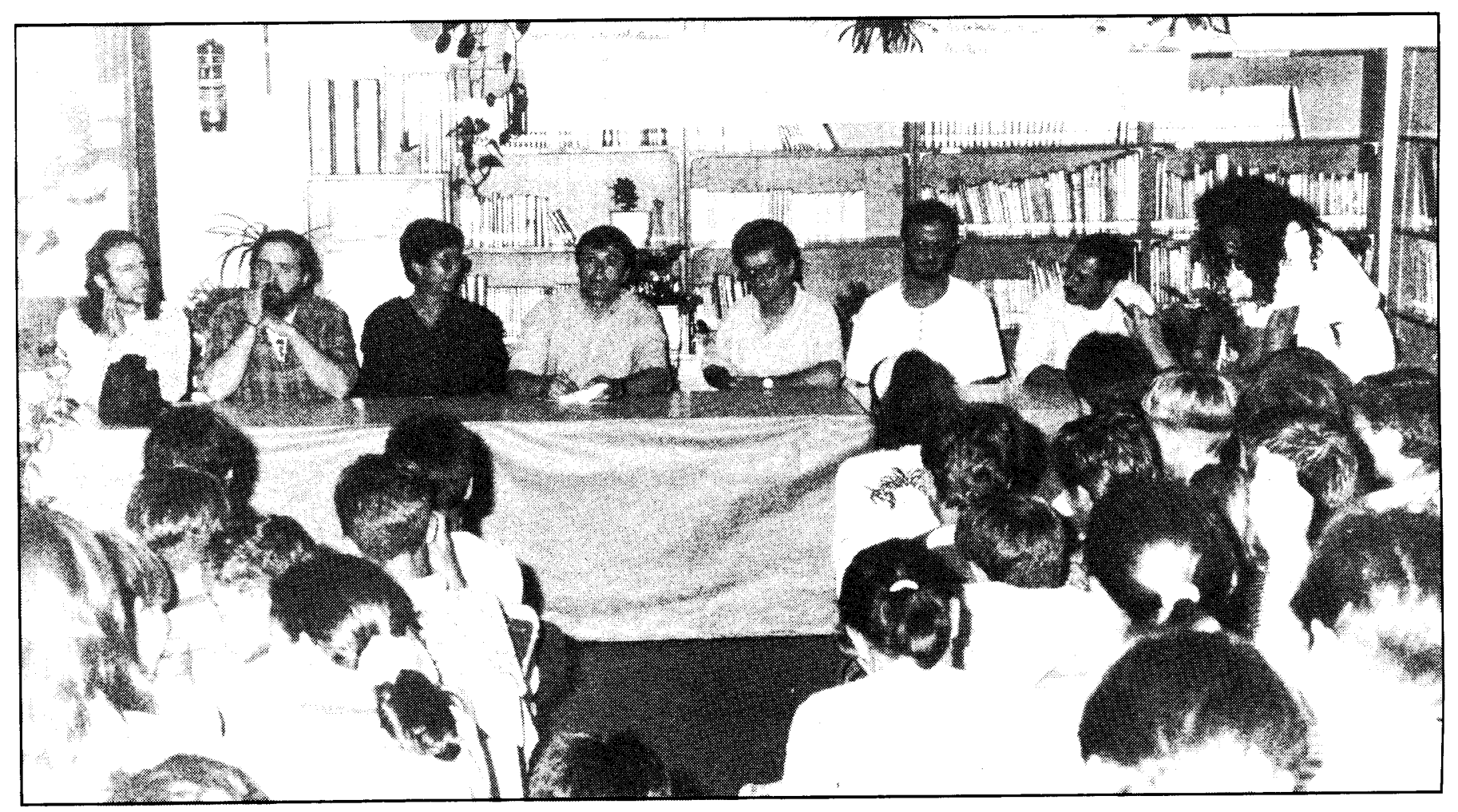






decidir, finalment, que treballariem amb els següents elements: Narrativa, Poesia, Pintura i Música. Les dues primeres eren fonamentals per donar un caire de seriositat curricular de cara als alumnes, ja que són matèries de pes dins l'àmbit escolar, i això, els nens ho saben. Allò que caldria fer era aconseguir que els nens trenquessin aquesta idea i copsessin la literatura com un art.

\section{3.- Passos a seguir. Planificació}

En primer lloc, el director va plantejar el projecte a tot el claustre de professors. Val a dir que un projecte d'aquestes caracteristiques no s'hauria pogut dur a terme sense l'ajut i la col.laboració de tot l'equip de professors. Aquest procés també es va seguir amb el consell escolar, del qual vàrem obtenir el seu consentiment i suport.

L'equip de professors que van haver de donar cos al projecte foren els que hi tenien més afinitat: Neus Turu (mestra de Llengua i Literatura), Josep Ramon Boix ( mestre de Plàstica) Angels Torras (Mestra de Música) i Joan Fuguet, que com a director va anar canalitzant el treball. Ens interessava fer un projecte experimental que ens fos vàlid i amb perspectives de continuïtat; per aquest motiu el vàrem delimitar al sisè nivell d'E.G.B, atès que serà el curs amb el qual s'acabarà l'ensenyament primari.

Com hem dit, preteníem no només parlar d'art, sinó fer art. Voliem, a més, trencar la rutina i el caire de matèria que ha agafat la literatura, i que els nens coneguessin l'artista. No havia de ser, però, un artista qualsevol. Si dèiem que el nen té dret a conèixer l'art que s'està fent a la seva ciutat i els artistes que el duen a terme, calia connectar amb aquesta gent. Aquest fou el primer pas. Vàrem exposar el projecte a un escriptor, un pintor, un poeta i un músic. La idea era que cada un d'ells realitzés una obra específica per a l'escola, fonamentada en un tema comú, de caire molt genèric, per tal de respectar la libertat de l'artista.

El grup d'artistes es van reunir per tal de posar-se d'acord sobre allò que els agradaria transmetre als nens. No en va sortir pas un sol tema, ni aquests eren tan senzills. Els seus punts de reflexió foren: La relació dels nens amb l'adult. El món dels grans vist des de l'òptica infantil. El sentiment de créixer i fer-se gran i La necessitat de tenir els propis errors.

A partir del regal que cada un dels artistes va oferir a l'escola, els alumnes van anar treballant sobre aquestes obres i les biografies dels seus creadors, per tal d'arribar a conèixer la persona, les seves motivacions i les seves creacions. Tot aquest treball es va realitzar en l'horari habitual de les classes i sense provocar desajustaments en altres assignatures que, per les seves caracteristiques, en restaven més aïllades.
Hi havia una colla de temes que vàrem haver d'estructurarivalorar, com ara:materials, espais, sistemes d'avaluació, horaris dels mestres, per tal de disposar d'alguns moments per anar-se trobant i poder valorar allò que anava passant.

\section{4.-Procés de treball a l'aula}

Abans de començar tot el treball a l'aula es va presentar el projecte als nens, se'ls va explicar com treballaríem, d'on podrien treure informació, se'ls va parlar de l'art i l'estètica... Es van produir diàlegs i intervencions dels nens molt avinents sobre l'estètica de la seva classe il'escola en general, sobre com treballarien més a gust, sobre el sorolls que a cops dificulten el treball i l'atenció... aspectes que sovint els mestres passem per alt. Arran d'aquestes intervencions, els nens van estructurar la seva aula de la manera que ells van trobar més estètica i còmoda per treballar.

Es va començar presentant els diferents artistes, ensenyant-los la fotografia, llegint les biografies i oferint un dossier de cada un d'ells, en el qual hi podien trobar la informació més diversa. Tot seguit es va proposar una recerca de materials i informació: Si els pares o amics coneixien algun dels artistes, si n'havien sentit parlar...

Es va començar a treballar sobre el conte que ens va regalar l'escriptor Magí Sunyer i Molné, titulat «Petits viatges" i que explica la història d'un nen que està constipat i la mare el fa quedar a casa uns dies. En Pere -aquest és el nom del protagonista - quan es comença a veure les orelles, surt de casa i es passeja per la ciutat mentre la seva mare és a treballar. En els seus petits viatges en Pere descobreix que la gent gran, quan treballa i no està amb els infants, és diferent.

En primer lloc es va donar el conte als nens i se'ls va dir que el deixessin llegir als seus pares, per tal que hi poguessin opinar. Aquesta va ser la primera sorpresa. Molts pares es van interessar pel conte i van escriure cartes a la mestra suggerint aspectes que es podrien treballar.

Es va fer una segona lectura en veu alta a classe, $i$ tot seguit es va passar al comentari del conte tocant diferents aspectes: Què us ha semblat? Podrieu dir una paraula o frase que reflecteixi la primera impressió que heu tingut? Per què creieu que ha posat aquest títol l'autor? lel Pere, com us l'imagineu? Sialgun nen vol, que el dibuixi i el porti. Tots el nens van dibuixar o retallar d'una revista un nen que els semblava que era el Pere i el van posar en un panell. La gran diversitat de Peres va donar peu a comentar l'aspecte interiorid'interpretació personal que implica una lectura.

Un nen de la classe va resultar ser el nebot de 


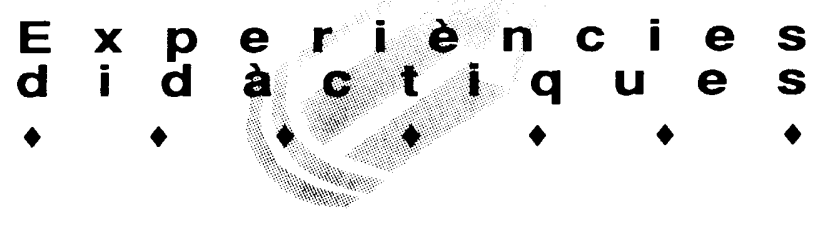

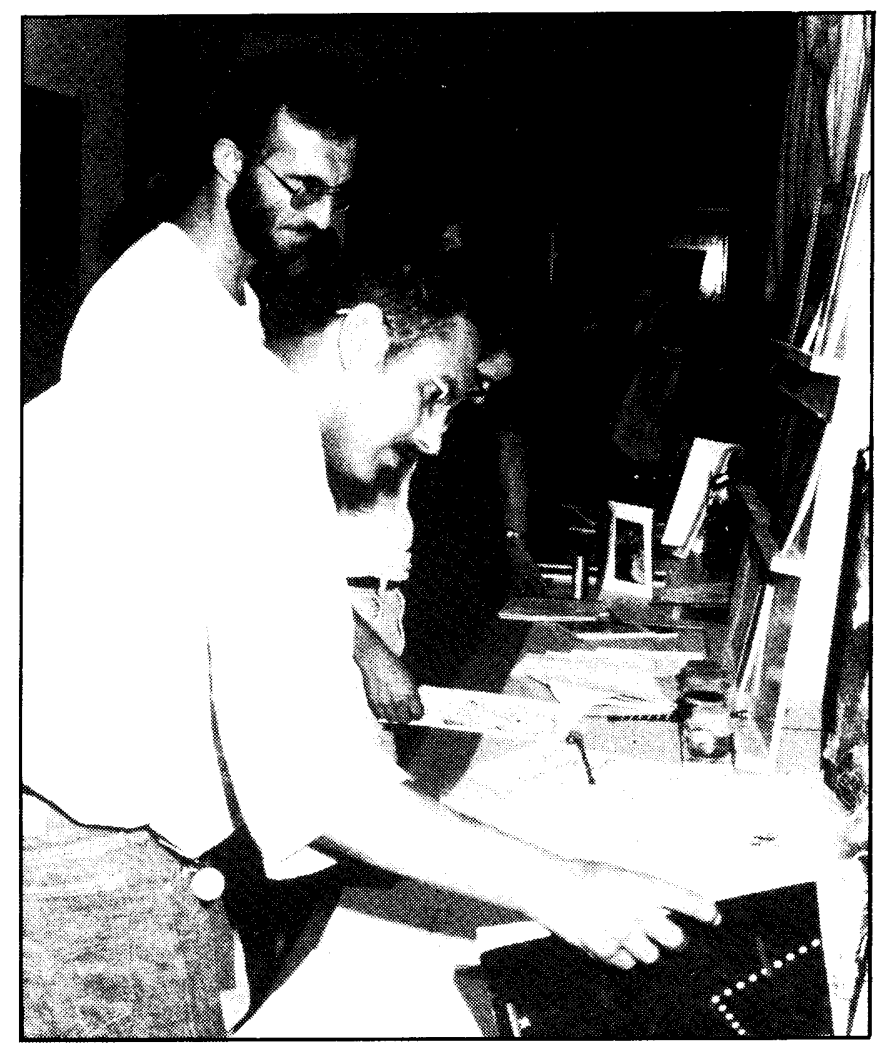

l'escriptor, i se li va encarregar que li fes una entrevista. Aquesta va ser llegida i comentada a classe i es va arxivar al dossier de consultes. Arran d'això alguns nens van descobrir que a l'escola hi havia nens que coneixien o tenien algun tipus de parentiu amb els artistes. La mestra els va proposar que investiguessin qui eren $i$ que els traguessin la informació que trobessin adient. A poc a poc el dossier d'informació s'anava omplint.

Endinsant-nos en un nivell més profund de treball, es va realitzar l'anàlisi literària de l'obra i es va parlar en particular del conte. A més de demanar als nens que trobessin el tema il'argument, es varen treballar aspectes formals: vocabulari, adjectius, comparacions..., aspectes de contingut: podem deduir de la lectura del text com actua el Pere, com és, quins llocs de Tarragona ha visitat...?

En finalitzar tot aquest procés se'ls va presentar el regal que ens havia fet el pintor Antoni Torrell i Camps. Es tracta d'un collage en el qual hi ha un nen dret sobre una peanya que està observant la ciutat. Els alumnes varen relacionar aquell nen amb el Pere del conte $\mathrm{i}$, alguns, el van situar en algun lloc concret de la ciutat. A partir d'aquí es va començar un debat sobre aspectes del quadre: la tècnica emprada (collage), les dimensions i proporcions d'alguns elements, la simbologia que podien tenir, aspectes de color...
A poc a poc els nens es varen anar endinsant en un tipus de lectura més suggestiva, i per boca d'en Pere anaven exposant les seves opinions. Es tocaren temes com ara: com són els grans, com es trobaria en Pere en la nostra escola, quines coses li deurien agradar fer, a què li agradaria jugar...

Ja que l'artista es dedica al collage, s'estudià concretament aquesta tècnica. Amb el professor de plàstica els nens es varen dedicar a realitzar diferents tipologies de collage, emprant els elements més diversos i sorprenents.

Mentre a l'aula de plàstica cada nen realitzava la seva pròpia creació, en les classes de llengua cada nen s'inventava un conte. Hi va haver nens que en varen realitzar un de nou amb una temàtica totalment diferent. Encanvi, d'altres varen preferir continuar el conte que ens va regalar el Magi i oferir-nos, aixi, la possibilitat de veure créixer i fer-se gran el nostre protagonista, "En Pere".

En un moment donat, se'ls va presentar el poema "Visions" de l'escriptor Joan Cavallé i Busquets:

\section{VISIONS}

He vist un rei que passejava per la plaça.

Un elefant s'ennuegava amb un got d'aigua.

Un caçador corria rere una formiga.

Un autobús s'alimentava de sardines.

Un sacerdot feia el bateig d'un diplodocus.

Un pescador quadriculava el mar a trossos.

Un general s'atemoria d'una aranya.

Un cocodril s'embetumava les sabates.

Un sol petit envermellia de vergonya

veient Saturn tot exhibint l'anell de bodes.

Un avió feia un forat al mapamundi

perquè Moisès, aigües avall, si pot ser suri.

Un lledoner s'alimentava amb coca amb panses

mentre la lluna es desvestia en quatre fases.

Un llop feroç es graduava les ulleres

per veure si la Caputxeta treia gepa.

Un rat-penat sintonitzava l'emissora

per controlar qui se les heu amb la lleona.

Un escriptor s'espavilava a escriure versos

sense saber si els llegirà cap xitxarel.lo.

Això i molt més he pogut veure aquesta tarda

quan, passejant, he travessat aquesta plaça.

Primerament el va llegir la mestra en veu alta, $i$ tot seguit el varen llegir els alumnes dient un vers cadascú. Els alumnes varen qualificar el poema com «una mena de cançó de les mentides" i de seguida es varen familiaritzar amb aquest codi que ratlla entre l'absurd il'il. lusori. Arran del poema, els nens varen posar el Pere en un altre 


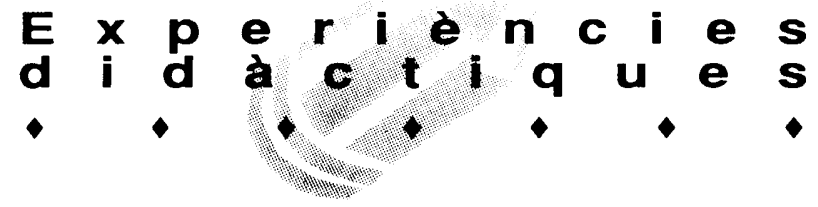

context ben diferent, més infantil, simpàtic i rialler. Cada nen va escollir un vers i el va il.lustrar.

En d'altres sessions de treball es va anar realitzant l'anàlisi del poema: ritme, versos, rima, vocabulari, tema, argument... Els nens varen opinar sobre el perquè d'aquest títol, sobre la relació que hi trobaven amb el conte i el collage, sobre la possibilitat de posar-hi música i fer-ne una cançó, sobre els poemes musicats... A partir d'aquí es varen oferir als nens poemes musicats d'en Joan Manuel Serrat i recitatius de l'Ovidi Montllor. Es convidà els nens a cercar alguna música que fos adient al poema per tal de realitzar-ne diferents sonoritzacions.

Paral.lelament a aquest procés, se'ls va presentar el regal que ens varen fer el grup de rock català "Els Pets". La cançó és titula «És qüestió de prioritats" amb lletra i música de Lluís Gavaldà. El tema de la cançó fa referència a una escala de valors diferent per a la joventut, en el dret de cometre els propis errors i escollir el propi cami.

En un primer pas se'ls va presentar la cançó perquè l'escoltessin. Se'ls va donar la lletra pel tal que la poguessin aprendre i cantar.

\section{ÉS QÜESTIÓ DE PRIORITATS}

Ells sempre em diuen que haig de treballar, que pensi en el dia de demà, que prengui exemple dels homes de profit que no descansen ni de nit. Fabriquen peles enganyant a qualsevol. Van enterrant velles il.lusions. Ho tenen tot tan ben organitzat, tant per avui com per demà.

Perquè ara estan en un altre món, una altra escala de valors. Això per mi no és important, és qüestió de prioritats.

Jo mentrestant ja tinc 22 anys complerts i me n'adono que no he fet res. Ja tindré temps de pringar sota d'algú, ara vull fer el que jo vull.

No vull que em marquin el camí fins al final, tot programat fins a l'últim detall:

deixeu que m'equivoqui, que no faig pas cap mal, ja ho trobareu al capdavall.

Perquè ara estan en un altre món, una altra escala de valors.

Això per mi no és important, és qüestió de prioritats.
En d'altres sessions de treball els nens varen reconèixer els diferents instruments (que ja havien estudiat anteriorment), van extreure la base rítmica de la bateria, varen reconèixer els fragments cantats en duets, la pulsació, la línia melòdica...A més dels aspectes musicals, es va treballar la lletra de la cançó seguint un procés similar al del poema esmentat anteriorment, i es va realitzar un debat sobre Els Pets: el tipus de música que fan, les lletres de les seves cançons... Varen sortir d'altres conjunts i cantants catalans, dels quals alguns nens ens varen portar les cintes per escoltar-les a classe o posarles a l'altaveu de l'escola.

\section{5.- Diada de cloenda}

Després de realitzar tot aquest treball i com a cloenda del projecte, el dia 1 de juny els diferents artistes varen acudir a l'escola per participar en una taula rodona. El director del centre va inaugurar l'acte establint les corresponents presentacions. Després, cada un dels artistes va fer un petit comentari sobre l'obra que havia realitzat, i seguidament es va obrir el torn de preguntes per part dels nens.

En el transcurs d'una hora els nens van "bombardejar" amb preguntes els diferents components de la taula sobre aquelles qüestions que més els van sobtar, motivar, captivar.... Anant més enllà de l'àmbit purament interrogatori, els alumnes van demanar explicacions $i$ interpretacions pel que fa a diferents elements de les obres, i varen suggerir noves interpretacions als seus autors.

Abans de finalitzar l'acte, dos alumnes varen obsequiar els artistes amb la lectura del conte "Petits Viatges-Il" de l'alumne J. Ignacio de las Cuevas, en el qual es continua la història a partir del punt on la va acabar l'escriptor Magí Sunyer, i amb la lectura del poema "Visions-II" de l'alumna Patrícia Moreno, on es presenta una continuïtat del poema realitzat per l'escriptor Joan Cavallé.

Al'acabament del'acte, els alumnes varen aproparse als artistesper demanar-los encara aquelles qüestions que no havien aclarit ,i per què no....el seu autògraf.

Per a aquesta ocasió es va muntar una exposició, on s'hi podien trobar tots els treballs realitzats pels nens (contes, poemes, pintures, dibuixos, els collages, les entrevistes realitzades als artistes o als seus coneguts, instruments musicals...) Els dossiers de classe, les biografies dels autors, programes dels concerts que han realitzat, llibrets de les exposicions que han fet, llibres que han publicat i, presidia l'espai, el quadre del pintor Antoni Torrell, que els nens han anomenat Pere, personatge que ja ha esdevingut popular en la nostra escola. 


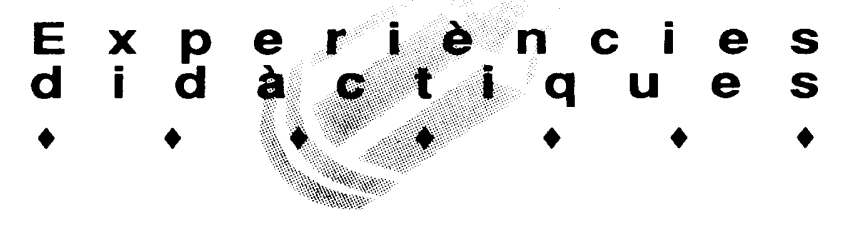

\section{6.- Control I avaluació}

Els problemes de la implantació es comencen a veure quan hi estem posats. Evidentment, hi ha molts aspectes que són previsibles is' han de planificar i preveure seriosament: horaris, espais, materials... però n'hi ha d'altres que s'han anat copsant a mesura que ens endinsàvem en el projecte.

El control i l'avaluació no té sentit al final del projecte, quan tot ja s'ha acabat. En tot cas, podem parlar d'una revisió final que ens introduirà al "feed-back" de cara a començar un nou procés, bé de perfeccionament i millora d'aquest o bé, si no ha funcionat com esperàvem, totalment diferent.

Durant tot el procés els mestres implicats han actuat com a observadors i han anat anotant diferents aspectes:

De cara als alumnes

- Si els nens hi tenen interès.

- Si hi gaudeixen, si els agrada.

- Si són crítics a l'hora de relacionar-se amb els artistes...

- Si s'ha aconseguit un clima de comunicació.

- Els problemes individuals dels alumnes: integració amb el grup, nivell de participació, dificultats per treballar en equip...

De cara al procés

- Validesa dels materials introduïts.

- Apreciació global de cada activitat.

- Alteració o canvis en la planificació original. artistes.

- Clima que s'aconsegueix en la relació nensvan utilitzant.

Com a estris d'avaluació i forma de recollir l'experiència, hem emprat des de fitxes d'observació i anecdotaris fins a enregistraments en vídeo de diferents moments del procés, fotografies dels treballs realitzats, dossier dels treballs dels alumnes i de les biografies dels diferents artistes, enregistrament de cassettes de les classes-col.loqui...

En acabar el procés, hem establert una avaluació de tipus genèric que reflecteixi l'opinió dels alumnes, dels professors que han viscut més directament el procés $i$ d'aquells que hi han estat més allunyats, dels pares que hi han participat i també dels artistes: què els ha semblat, com s'han sentit, ho han trobat interessant, profitós...?

A través d'aquesta revisió final, en la qual encara estem treballant, podrem establir les dimensions i el caire que haurà de prendre aquesta activitat de cara al proper curs. Properament en donarem més notícia.

\section{7.- Conclusions}

Com dèiem anteriorment, el nostre projecte originari era força ambiciós $\mathrm{i}$, encara que valorem tot el treball realitzat molt positivament, hauriem de ser justos exposant allò que vàrem retallar. A més de globalitzar més arts $i$ implicar-hi més artistes, el projecte inicial no acabava aqui. S'havia pensat de planificar, durant la setmana següent a la taula rodona, tallers de pintura, música, poesia i creació de contes sota el lliure mestratge de cada un dels artistes.

Com hem dit abans, ens hauria agradat poder realitzar una globalització completa, és adir: que el text, la música, la pintura, la dansa, el teatre...coincidissin en un mateix punt. Pensàvem més aviat en un espai buit que s'aniria omplint de veu, sons, pintures, estris i coses que serien, en definitiva, l'escenari per recitar poemes, fer dansa... Com hem dit, això suposa comptar amb un espai, materials i temps que, ara per ara, no teníem.

Per a començar a caminar vers una idea diferent d'ensenyar, l'art no està malament, però... això només serà començar. Caldrà que, de cara al curs que ve, es pugui avançar una mica més. Aquest any, i a tall experimental, deixem-ho així. Gairebé a les acaballes del curs, aquests projecte ens mena a la ratificació que a l'escola cal educar el nen dintre d'una concepció estèticoartística de caire holístic. Tot això és possible si els nens tenen uns models vius i propers, personatges que caminen per la rambla un diumenge o que es poden trobar a la cua del cinema.

Des d'aquí volem deixar constància del nostre agraïment al grup d'artistes que han fet possible, desinteressadament, aquest projecte, i encoratjar d'altres col.lectius de mestres per tal que s'endinsin en aquesta línia de treball.
Angels Torras i Albert. (Professora de Música del C.P.de Pràctiques de Tarragona) 